peritoneal dialysis in advanced liver disease complicated by hyponatraemia no improvement in renal function or hepatic encephalopathy was seen. ${ }^{+}$Thirteen of the 16 patients in this series died, two from complications of the peritoneal dialysis technique.

Arteriovenous haemofiltration is an extracorporeal technique which allows removal of fluid, electrolytes, and small to medium sized molecules by plasma ultrafiltration.' A single filter used for several days allows continuous readjustment of fluid and electrolyte treatment. Clotting of the filter during periods of hypotension in the patient was the only problem encountered during filtration.

Continuous arteriovenous haemofiltration combined with infusion of isotonic saline is of value in correcting severe hyponatraemia in patients with established hepatorenal syndrome who urgently require liver transplantation. Failure to correct hyponatraemia before operation may precipitate central pontine myelinolysis. Using continuous arteriovenous haemofiltration to correct hyponatraemia safely allowed successful liver transplantation without neurological sequelae.

1 Sterns RH, Riggs JE, Schochet SS. Osmotic demyelination syndrome following correction of hyponatremia. $N$ Engl f Med 1986;314:1535-42.

2 Adams DH, Ponsford S, Gunson B, et al. Neurological complications following liver transplantation. Lancet 1987; i:949-51.

3 Arroyo V, Rodes J, Gutierrez-Lizarraga MA, Revert L. Prognostic value of spontaneous hyponatraemia in cirrhosis with ascites. Digestive Dis 1976;21: $249-56$

4 Ring-Larsen H, Clausen E, Ranek L. Peritoneal dialysis in hyponatremia due to liver failure. Scand $\mathcal{F}$ Gastroenterol 1973;8:33-40.

5 Kramer P, Wigger W, Rieger J, Matthaei D, Scheler F. Arteriovenous haemofiltration: a new and simple method for treatment of overhydrated patients resistant to diuretics. Klin Wochenschr 1977;55:1121-2.

(Accepted 13 September 1988)

\title{
Inflammatory cells in the airways in mild asthma
}

\section{S Lozewicz, E Gomez, H Ferguson, R J Davies}

St Bartholomew's Centre for Clinical Research, Department of Respiratory Medicine, St

Bartholomew's Hospital, London EC1A 7BE

S Lozewicz, MD, research

fellow

E Gomez, BSC, research assistant

H Ferguson, BSC, research assistant

R J Davies, FRCP, reader in respiratory medicine

Correspondence to: $\mathrm{Dr}$ Davies.
The possibility that hyperresponsiveness of the airways in asthma might be related to inflammation of the airways has been of increasing interest recently. ' Postmortem examination of patients who died of acute asthma showed inflammatory changes in the bronchial mucous membrane, but little information is available on the histology of the airways in mild asthma. We therefore examined specimens of bronchial mucous membrane taken from patients with mild asthma and airway hyperresponsiveness and from healthy controls without airway hyperresponsiveness.

\section{Patients, methods, and results}

Approval was obtained from the ethical committee of St Bartholomew's Hospital. We studied 10 asthmatic volunteers (three men; mean age 26.4 years (range 21-39) and nine healthy volunteers (five men; mean age 24 years (range 20-32)). Only the asthmatic subjects were atopic as judged by one or more positive responses on skin prick tests to five common inhalant allergens. All the subjects with asthma (but none without asthma) showed airway hyperresponsiveness to inhaled methacholine, defined as a provocation dose necessary to produce a $20 \%$ fall in forced expiratory volume in one second of $<8 \mathrm{~mol}^{2}$ None of the
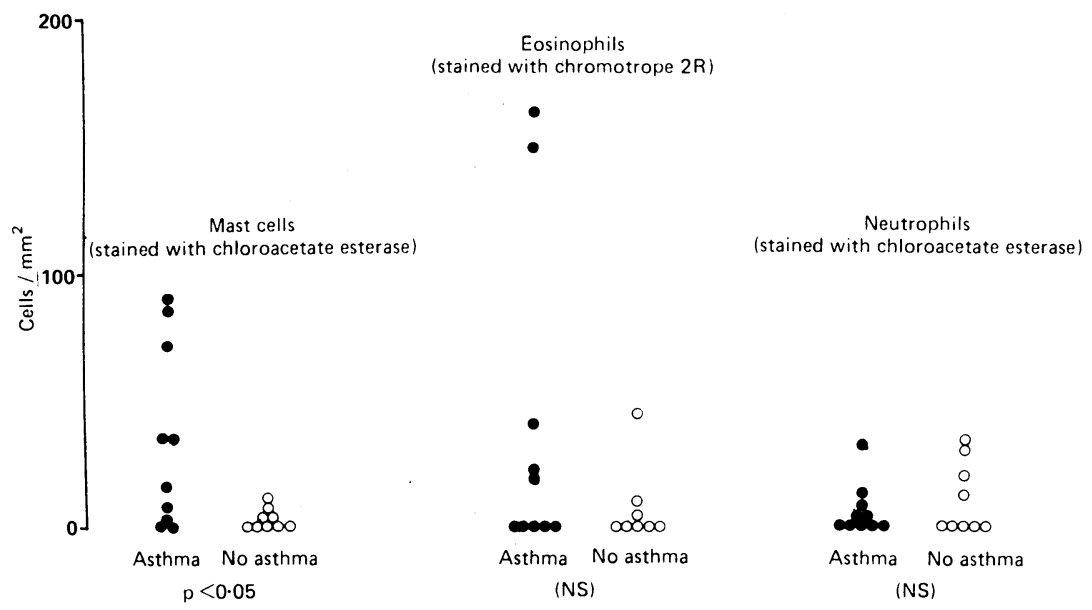

Cell counts per $\mathrm{mm}^{2}$ of tissue section of lamina propria of bronchial mucous membrane in 10 subjects with asthma and nine subjects without asthma. One value for eosinophils in healthy subjects is missing. Subjects with asthma had significantly more mast cells $(p<0.05)$ subjects with asthma required corticosteroids; four took inhaled salbutamol every day and six took it less frequently. All subjects were non-smokers.

Fibreoptic bronchoscopy was performed and cup forceps used to take up to four biopsy specimens of the mucous membrane from the right upper and right middle lobe carina. One adequate specimen was immediately fixed in Carnoy's solution for staining with $\alpha$-naphthol AS-D chloroacetate esterase for mast cells and neutrophils and another was fixed in formaldehyde and stained with Chromotrope 2R (BDH Chemicals) for eosinophils.

The subjects with asthma had significantly more mast cells in the lamina propria (median $24 v 0$; $\mathrm{p}<0.05)$. They also had more eosinophils, but the difference was not significant, and the number of neutrophils was similar in each group (figure). Healthy and asthmatic subjects did not differ significantly in counts of epithelial cells, and the magnitude of bronchial hyperresponsiveness was not correlated with the numbers of mast cells, eosinophils, or neutrophils in the epithelium or lamina propria.

\section{Comment}

This study showed greater numbers of mast cells in the airway mucosa of patients with mild atopic asthma and airway hyperresponsiveness than in people without asthma. As atopy is associated with airway hyperresponsiveness ${ }^{3}$ the increase in the number of mast cells might relate to either atopy or hyperresponsiveness, or both. Although recent reviews on the pathogenesis of asthma emphasise the putative importance of the mast cell, ${ }^{4}$ there have been few supporting histological data. In previous studies airway tissue obtained from patients with asthma at bronchoscopy was fixed in formaldehyde or glutaraldehyde, which have been shown to inhibit the staining of mast cells of the mucosal type, which predominate in the human respiratory tract. This may account for the failure of previous studies to find increased numbers of mast cells in the airway mucosa of patients with asthma. We stained mast cells in tissue fixed in Carnoy's solution, which is recommended for the study of mucosal type mast cells.

Eosinophils may produce bronchial damage by the release of toxic proteins such as major basic protein. The number of eosinophils was not significantly higher in our asthmatic subjects, but deposits of major basic protein have been shown in the absence of increased numbers of eosinophils.

The influx of neutrophils into the airways might play a part in the development of bronchial hyperresponsiveness. ${ }^{1}$ In our study the number of neutrophils in the bronchial mucous membrane was similar in 
asthmatic and healthy subjects, indicating that increased numbers of neutrophils in the airways could not account for the bronchial hyperresponsiveness, which was present in all of our asthmatic subjects.

1 Boushey HA, Holtzman MJ. Experimental airway inflammation and hyperreactivity: searching for cells and mediators. Am Rev Respir Dis 1985;131 312-3.
2 Bennett JD, Davies RJ. A comparison of histamine and methacholine bronchial challenges using the DeVilbiss 646 nebuliser and the Rosenthal-French dosimeter. BrF Dis Chest 1987;81:252-9.

3 Woolcock AJ, Peat JK, Salome CM, et al. Prevalence of bronchial hyper responsiveness and asthma in a rural adult population. Thorax 1987;42:361-8. Kay AB. Inflammatory cells in acute and chronic asthma. Am Rev Respir Dis 1987; 135:S63-6.

5 Peters MS, Schroeter AL, Gail M, et al. Localization of eosinophil granule major basic protein in chronic urticaria. F Invest Dermatol 1983;81:39-43.

(Accepted 6 September 1988)

\section{British Caledonian} Airways, Crawley, West Sussex RH10 2XA Michael Glanfield, $M B$, medical officer

Correspondence to: 1 The Drive, West Wickham, Kent BR4 0EP.

\section{High altitude testing of pulse oximeter}

\author{
Michael Glanfield
}

Portable pulse oximeters are a useful monitoring tool for air ambulance work. Over the past 15 months I have used an oximeter (the Nellcor N-10 unit) when monitoring patients returning to Britain in a wide range of civil aircraft including a Lockheed Tristar, Boeing 737, Lear 35, De Havilland Twin Otter, Bandeirante, BAC 1-11, and Dash-7. The unit worked reliably in all these aircraft and gave results that were similar to those predicted up to the maximum altitude on these flights (11000 feet; $3350 \mathrm{~m}$ ). I tested whether the oximeter would work at higher altitudes and also noted the subjective effects of exposure to altitude hypoxia.

\section{Method and results}

The Cessna 310 is a twin engined unpressurised aircraft that can climb to a maximum altitude of 27400 feet $(8350 \mathrm{~m})$. I used myself as a fit, unacclimatised subject with a normal haemoglobin concentration $(147 \mathrm{~g} / \mathrm{l})$ and made readings of arterial oxygen saturation and pulse rate every $150 \mathrm{~m}$ up to 24100 feet $(7350 \mathrm{~m})$. At this altitude my mental performance deteriorated considerably, and I was given $60 \%$ oxygen by mask. I continued to make readings up to 27000 feet $(8235 \mathrm{~m})$, when the aircraft was unable to climb any more.

The figure shows the changes in oxygen saturation

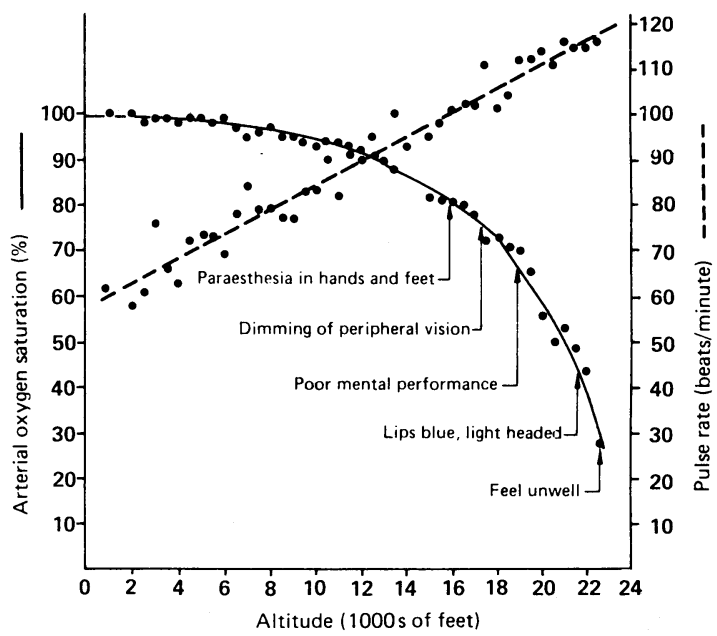

Arterial oxygen concentration, pulse rate, and physical and mental symptoms with increasing altitude over 63 minutes

and pulse rate and the symptoms of hypoxia with altitude. Below a saturation of $50 \%$ the oximeter gave a delayed reading and therefore could not be considered reliable or easy to use. Above $50 \%$ saturation, both during the ascent and at high altitude when I was receiving oxygen, the unit was reliable and seemed unaffected by the change in pressure.

\section{Comment}

The Nellcor $\mathrm{N}-10$ pulse oximeter worked reliably up to an altitude of 27000 feet $(8235 \mathrm{~m})$, although it was difficult to use at oxygen saturations below $50 \%$.

(Accepted 5 May 1988)

\section{Current practice in managing urinary tract infections in children}

\section{Rosalind L Smyth, L Berman, H B Valman}

Department of Paediatrics, Ipswich Hospital, Suffolk IP4 5PD

Rosalind L Smyth, MRCP, registrar

Northwick Park Hospital, Middlesex HA1 3UJ

L Berman, FRCR, senior registrar in radiology

H B Valman, FRCP, consultant paediatrician

Correspondence to: Dr Valman.
The management of urinary tract infections in paediatrics is controversial. Recently, with the advent of sophisticated imaging techniques, many different diagnostic pathways have been advocated. ${ }^{12}$ We conducted a survey of paediatricians in both district general and teaching hospitals to elucidate current practice in the United Kingdom.

\section{Methods and results}

From a total of 745 consultant paediatricians 120 were randomly selected and sent a detailed questionnaire concerning the investigation, treatment, and follow up of children with urinary tract infections. Ninety eight consultants (82\%) replied, including
16 who were not concerned with managing these infections, one who did not complete the questionnaire, and two who completed one questionnaire between them. Thus we analysed a total of 80 questionnaires.

The table shows the responses to five questions. A further question concerned the investigations that were performed after a proved infection had been found and whether they depended on sex and the number of infections. The results were analysed into broad categories: 22 respondents routinely obtained only an ultrasound scan or an intravenous urogram; 26 obtained an ultrasound scan or a urogram in all patients and a micturating cystourethrogram either in all patients or in those below a specified age; 17 obtained an ultrasound scan or an intravenous urogram, a cystourethrogram, and either a diethylenetriamine penta-acetic acid (DTPA) scan or a succimer (DMSA) scan; 11 obtained an ultrasound scan or a urogram and a cystourethrogram and requested diethylenetriamine penta-acetic acid or succimer scans if the results of any of the first three were abnormal; and four gave replies that did not fit into any of the above categories.

Thirty three respondents thought that boys should 